\title{
Условные обозначения (маркировка) строительных материалов и конструкций для информационного использования на всех этапах жизненного цикла
}

\author{
Н.Г.Келасьев, ЦНИИПромзданий, Москва \\ Э.Н.Кодыш, ЦНИИПромзданий, Москва \\ Н.Н.Трекин, ЦНИИПромзданий, Москва \\ И.А.Терехов, ЦНИИПромзданий, Москва \\ С.Д.Шмаков, ЦНИИПромзданий, Москва \\ А.Б.Чаганов, ВятГУ, Киров
}

В статье рассматривается система классификации строительных материалов и конструкций. Представлены основные преимущества и недостатки существующих систем кодирования информации для использования при идентификации строительных элементов и материалов. Рассмотрены наиболее широко распространённые зарубежные системы классификации и идентификации, применяемые при работе с информационными моделями отдельных конструкций, а также зданий и сооружений, такие как «0мникласс» (OmniClass, США), «Юникласс 2015» (Uniclass 2015, Великобритания), а также опыт Дании в разработке систем классификации. Выявлены основные особенности и потребности содержания информации при проектировании с использованием системы информационной модели объекта строительства, что позволило представить к обсуждению методику построения универсального классификатора-идентификатора, выполненного по типу открытой иерархической системы маркировки, основанной на ранее разработанных и применяемых в России системах классификации и идентификации, таких как Классификатор строительных ресурсов, Рубрикатор строительного каталога, Условные обозначения типовых конструкций и др. Применение методики позволяет частичное использование существующих строительных каталогов, что ведёт к снижению стоимости разработки информационной базы и внедрения классификатора. Построенный по данной методике классификатор может быть применён для однозначного определения и классификации строительной системы на всех этапах жизненного цикла. Классификатор способен предоставлять пользователю исчерпывающий набор данных об объекте классификации, применяться для классификации элемента, конструкции, узла сопряжения, материала или иной части строительной системы, в т.ч., при работе с информационными моделями объектов строительства. Внедрение единой системы классификации позволит снизить трудоёмкость на всех этапах работы с информационной моделью, будет способствовать технически грамотной эксплуатации, обеспечивающей нормативный срок службы зданий и сооружений.
Ключевые слова: условное обозначение, маркировка, информационная модель, классификатор, методика, ВIM, материал, изделие, конструкция.

Conventions (Marking) of Construction Materials and Structures for Information Use at All Stages of the Life Cycle

N.G.Kelasiev, TSNIIPromzdanii, Moscow

E.N.Kodysh, TSNIIPromzdanii, Moscow

N.N.Trekin, TSNIIPromzdanii, Moscow

I.A.Terekhov, TSNIIPromzdanii, Moscow

S.D.Shmakov, TSNIIPromzdanii, Moscow

A.B.Chaganov, VyatSU, Kirov

The article deals with the classification system of building materials and structures. The main advantages and disadvantages of existing information coding systems for use in the identification of building elements and materials are presented. The most common foreign classification and identification systems used when working with information models of individual structures, as well as buildings and structures, such as OmniClass (USA), Uniclass 2015 (UK), as well as the experience of Denmark in the development of classification systems, are considered. The main features and needs of information content in the design using the BIM model of the construction object were identified, which allowed to present for discussion the methodology for constructing a universal classifier-identifier, made in the form of an open hierarchical marking system based on previously developed and used in Russian classification and identification systems, for example, the classifier of building resources, the categorizer of the building catalog, symbols for typical structures, and so on. The use of this method allows partial use of existing construction catalogs, which reduces the cost of developing an information base and implementing a classifier. A classifier based on this method can be used to uniquely identify and classify a building system at all stages of its life cycle. The classifier can provide the user with a comprehensive set of data about the classification object, and can also be used to classify an element, structure, interface, material, or other part of the 
construction system, including when working with information models of construction objects. The introduction of a unified classification system will reduce the complexity at all stages of working with the information model and will contribute to technically competent operation that ensures the standard service life of buildings and structures.

Keywords: symbol, marking, information model, classifier, methodology, BIM, material, product, construction.

\section{Введение}

Знак принадлежности - клеймо, появился в глубокой древности. В наше время идентификация товара может осуществляться товарным знаком, который бывает словесным, изобразительным или комбинированным.

В торговой сети в настоящее время широко используются штрихкоды - графическая информация, наносимая на поверхность изделия или упаковку и считываемая техническими средствами. Штрихкод (рис. 1) содержит информацию о организации-регистраторе, сведения о предприятии, выпускающем продукцию, код товара и т.д.

Даже сам факт появления штрихкодов подтверждает, что во всех отраслях промышленности происходит технологическая революция. Захватила она и строительство. Если раньше директивные нормы, детализирующие все процессы и исходные свойства материалов, могли обеспечить требуемую безопасность и качество продукции, то теперь такой подход невозможен. Регулярно появляются материалы с новыми свойствами, прогрессивные технологии производства работ, автоматизируются все процессы, включая проектирование, усовершенствуются машины и механизмы. Организации, разрабатывающие нормативные документы, и законодатели не в состоянии учесть в документах все эти новшества при традиционном подходе к нормированию.

Этап проектирования объекта претерпел также большие изменения. Широкое внедрение BIM-технологий (Building Information Modelling), которые позволяют обеспечить предусмотренные свойства объекта на всех этапах жизненного цикла, потребовало усовершенствования и классификации исходных данных, в том числе материалов и конструкций.

На наиболее протяженном этапе - эксплуатации, а также этапах капитального ремонта и реконструкции необходимо

5

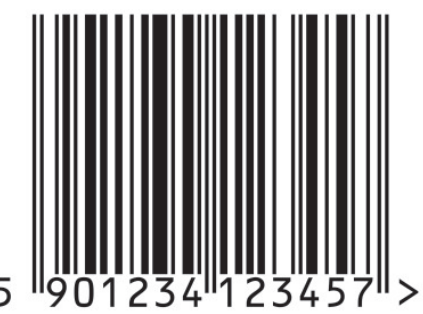

a)

Puс. 1. Маркировка штрихкодом: а) линейный штрихкод; б)

двухмерный штрихкод иметь подробную информацию о характеристиках, свойствах, возможных воздействиях, нагрузках и долговечности конструкций и материалов. Эти сведения должны содержаться в маркировке конструкций и материалов.

Системы классификации и кодирования информации

В строительной отрасли нашей страны нормативные требования к информационным сведениям об изделиях содержались в ГОСТ 2.314-68 «Единая система конструкторской документации. Указания на чертежах о маркировании и клеймении изделий». В 2007 году ГОСТ был переиздан с учётом ранее утверждённых изменений. В развитие этого базового ГОСТ были разработаны: ГОСТ 23009-2016 «Конструкции и изделия бетонные и железобетонные сборные. Условные обозначения (марки)» и ГОСТ 26047-2016 «Конструкции строительные стальные. Условные обозначения (марки)».

Согласно ГОСТ 23009 марка состоит не более чем из трёх буквенно-цифровых групп, разделённых дефисами, и содержит обозначения основных характеристик конструкций и изделий.

Первая группа содержит: обозначение типа конструкций; определяющие габаритные размеры и/или обозначения типоразмеров конструкции.

Вторая группа включает: несущую способность конструкции; класс и отличительные свойства основной рабочей арматуры (пример отличительных свойств: С - свариваемость); вид бетона (пример: Л - лёгкий бетон).

Третья группа содержит дополнительные характеристики, отражающие особые условия применения: 1 - стойкость к воздействию агрессивных сред; 2 - сейсмостойкость; 3 - стойкость к повышенным и высоким температурам; 4 - конструктивные особенности (наличие дополнительных закладных изделий, отверстий и т.д.). В этой группе допускается приводить другие характеристики, отражающие особые условия применения конструкций и изделий.

В 2016 году был разработан ГОСТ 26047-2016 «Конструкции строительные стальные. Условные обозначения (марки)». В стандарте применены буквенные обозначения по ГОСТ 2.32184 «Единая система конструкторской документации (ЕСКД). Обозначения буквенные», а также сокращения: КМ - чертежи металлических конструкций; КМД - деталировочные чертежи металлических конструкций.

Предусмотрено четыре различных структуры марок: 1 - конструкции в чертежах КМ конкретных объектов; 2 типовые конструкции в чертежах КМ, конструкции в ГОСТ и ТУ; 3 - конструкции в чертежах КМД, в том числе типовых конструкций; 4 - готовые конструкции и изделия. В приложении приведены буквенные обозначения наименований основных конструкций и изделий.

Условные обозначения деревянных конструкций приведены в ГОСТ 21.504-2016 «Система проектной документации для строительства. Правила выполнения рабочей документации деревянных конструкций» и содержат буквенные обозначе- 
ния типов конструкций. К ним добавляется порядковый номер данного типа конструкции. Например, А1 - арка первая с начала отсчёта. Условные обозначения конструкций содержатся также в документе: «Рубрикатор строительного каталога. 4. 3. Типовая документация на строительные системы и изделия зданий и сооружений» ${ }^{1}$.

В нём осуществлена попытка разработки единой системы классификации и присвоения обозначений типовой документации на строительные системы и изделия зданий и сооружений.

Кодовое обозначение состоит из шести частей.

1 часть - раздел. В рубрикаторе содержится девять разделов. Отдельные разделы посвящены конструкциям зданий, конструкциям сооружений, инженерному оборудованию для них, информационным материалам. Предусмотрен резерв разделов. После этой цифры раздела ставится точка.

2 часть - подраздел. Состоит из трёх цифр. Обозначает функциональное назначение здания и обозначается цифрами от 0 до 8. Это вторая цифра после цифры раздела. Так, например, 1.100 - здания жилые, 1.200 - общественные здания, а 1.800 - сельскохозяйственные производственные здания; 4.600 - узлы сооружений связи; 7.200 - инженерное оборудование, изделия и узлы инженерного оборудования сооружений гражданского строительства и т.д. Подраздел делится на группы (третья цифра), а они в свою очередь на подгруппы (четвёртая цифра). Например, 1.200 - каркасы (комплексные решения), в этой группе подгруппы:

1.121 - резерв; 1.122 - рамы; 1.123 - колонны и связи по ним... 1.128 - диафрагмы жёсткости. 7.902 - канализация в составе санитарно-технических систем сооружений. 0 означает что она может применяться в нескольких видах строительства (универсальность применения).

Пятая цифра характеризует материал конструкций: 1 бетон и/или железобетон, 2 - стальные... 6 - из кирпича и естественного камня и т.д.

В необходимых случаях к обозначению добавляется буквенный индекс, характеризующий особые условия строительства: с - сейсмичность, п - просадочные грунты. Последняя часть - порядковый номер серии типовой документации в составе группы или подгруппы. В качестве примера приведём обозначение серии: «Панели перекрытий лоджий пяти и девятиэтажных жилых зданий со стенами из кирпича и крупных блоков. Для строительства на просадочных неравномерно сжимаемых грунтах и подрабатываемых территориях» - 1.137.1-4пв, где: 1 - раздел «Строительные конструкции и изделия зданий»; 1 - подраздел «Жилые

здания»; 37 - подгруппа «Эркеры, лоджии, балконы» в составе группы «Стены и перегородки»; 1 - характеристика материала конструкции - железобетонные; 4 - порядковый номер серии типовой документации в составе подгруппы 1.137; пв - обозначение особых условий строительства - просадочные, неравномерно сжимаемые грунты и подрабатываемые территории.

Для нормативных документов принят Общероссийский классификатор стандартов $(0 К С)^{2}$, который гармонизирован с Международным классификатором стандартов (МКС) и Межгосударственным классификатором стандартов ${ }^{3}$. Он также имеет иерархическую структуру, состоящую из трёх ступеней (разделов). Вначале классифицируют предметы области с дальнейшим делением на группы и подгруппы.

Пример: 91.080.10, где 91 - Строительные материалы и строительство; 080 - Конструкции зданий; 10 - Металлические конструкции.

В России был разработан Классификатор строительных ресурсов (КСР). Он синхронизирован со Статистической классификацией продукции по видам деятельности в Европейском экономическом сообществе (СРА 2008) 4 и Общероссийским классификатором продукции по видам экономической деятельности (ОКПД2) 0К034-2014 (КПЕС 2008), который был утверждён в 2014 году Федеральным агентством по техническому регулированию и метрологии. КСР позволяет осуществлять анализ и обмен информацией с различными организациями, в том числе зарубежными. В КСР использован иерархический метод классификации и последовательный метод кодирования. Код содержит от двух до 17 цифровых знаков. Предельное количество книг в классификаторе может достигать 99. Ресурсы в Классификаторе строительных ресурсов привязаны к соответствующим группировкам по кодам 0КПД2 (КПСЕ2008). В конце кода классификации может быть добавлен нормативный срок эксплуатации материала (табл. 1).

Таблица 1. Пример классификации

\begin{tabular}{|l|l|l|}
\hline Код ОКПД2 & 23.63 .10 & Смеси и растворы строительные \\
\hline Книга & 04 & $\begin{array}{l}\text { Бетоны, растворы, смеси } \\
\text { строительные и асфальтобетонные }\end{array}$ \\
\hline Часть & 04.1 & Бетоны готовые к употреблению \\
\hline Раздел & 04.1 .01 & Бетоны легкие \\
\hline Группа & 04.1 .01 .1 & Бетоны на пористых заполнителях \\
\hline
\end{tabular}

${ }^{1}$ Перечень проектной документации типовых строительных конструкций, изделий и узлов зданий и сооружений для всех видов строительства. П-3.02015. - М. : Изд. ОАО «Центральный институт типового проектирования им. Г.К. Орджоникидзе», 2015. - 298 с.

${ }^{2}$ Общероссийский классификатор стандартов ОК (МК (ИСО/инфко МКС) 001-96) 001-2000.

${ }^{3}$ Межгосударственный классификатор стандартов МК (ИСО/ИНФКО МКС) 001-96.

${ }^{4}$ Статистическая классификация продукции по видам деятельности в Европейском экономическом cooбществе (Statistical Classification of Products by Activity in the European Community, 2008 version). 


\section{Системы классификации для ВIM-технологий}

Для перехода на современные технологии ВIMпроектирования экономически развитые страны разрабатывают новые системы классификации.

Так, в США применяется система OmniClass или OCCS5. Эта огромная система включает другие существующие системы. Для описания результатов работы используется система Master Format, для элементов - Uniformat, и EPIC - для структурирования продуктов. Система может применяться во всех отраслях, вплоть до организации библиотечного хозяйства. Система состоит из 15 таблиц, каждая из которых описывает определённую область строительной отрасли. Элементы таблиц могут применяться самостоятельно или в комплексе, описывая сложные объекты. Коды элементов содержат не менее четырёх пар символов. Правая пара всегда обозначает номер таблицы. Система носит открытый характер и может дополняться.

Система «Uniclass 2015» [7] в Великобритании применяется для всех секторов строительной отрасли, включая инфраструктуру, инженерные сети, гражданское строительство и т.д. Она основана на международном нормативном документе IS0-12006-27 и содержит элементы информационной модели на всех этапах жизненного цикла.

В России документ IS0-12006-2 прошёл стадию гармонизации и введён в действие под наименованием ГОСТ Р ИСО 12006-2-2017 «Строительство. Модель организации данных о строительных работах. Часть 2. Основы классификации информации». Стандарт определяет основу для разработки классификационных систем и содержит набор рекомендованных наименований классификационных таблиц для ряда классов в соответствии с рассматриваемым признаком, а также показывает, насколько классы предметов связаны между собой как серии систем и подсистем, например в информационной модели здания.

В стандарте не приведена полная классификационная система и содержание таблицы, но имеются необходимые примеры.

Стандарт распространяется на полный жизненный цикл здания, включая составление технического задания, предпроектную подготовку, разработку документации, строительство, эксплуатацию и снос.

В стандарте представлена разбивка на классы с указанием основных связей между ними.

В Дании был разработан стандарт-классификатор в соответствии с требованиями ISO 81346 «Промышленные системы, установки, оборудование и промышленная продукция. Принципы структурирования и кодовые обозначения» («Industrial systems, installations and equipment and industrial products - Structuring principles and reference designations»), который является основой для разработки ВIM-программы. Все элементы, включённые в программу, имеют набор обязательных свойств (характеристик). Эта система позволяет использовать идентификационную информацию на всех этапах жизненного цикла. В IS0 81346 около 600 классов, подклассов, подподклассов, обозначающих элементы, изготавливаемые как на заводе, так и на стройплощадке. Классификатор состоит из трёх основных классов и характеризуется включением в код одной, двух и трёх букв соответственно: 1 - классы функциональных систем - X (покрытия, стены, перекрытия и т.д.); 2 - классы технических систем - XX (стропильная система, стены наружные и т.д.); 3 - классы компонентов - XXX (плита, изоляционный материал, окно, механизмы открывания и закрывания).

\section{Универсальная классификационная методика}

Анализ Единой системы классификации и кодирования технико-экономической и социальной информации Российской Федерации (ЕСКК) и отчёта о НИР «Разработка методики классификации строительных материалов, изделий и конструкций, и определения нормативных сроков их эксплуатации» $и$ материалов $[1 ; 3 ; 5 ; 6 ; 7]$ позволяет сделать вывод о том, что современная классификационноидентификационная система, применяемая в строительстве, должна включать следующие характеристики и параметры: функциональное назначение объекта строительства, его расчётный срок службы, назначение элемента конструктивной и инженерной системы, системы сетей, расчётный срок службы рассматриваемого элемента, нагрузки и воздействия, а также материалы и их свойства.

Учитывая длительный срок эксплуатации, целесообразно рассматривать возможность сохранения этих данных, в том числе в электронном виде, в государственной организации, например в бюро технической инвентаризации (БТИ).

Нагрузки и воздействия являются комплексной информацией, которая должна содержать несколько стадий: доэксплуатационную (собственный вес, транспортные, монтажные и др.), эксплуатационную (собственный вес, технологические, сейсмические, коррозионные, специальные, аварийные, особые). К примеру, специальные характеристики могут включать воздействия радиационные, температурные, акустические и т.д.

Ниже представлена для обсуждения универсальная классификационная методика, способная предоставлять пользователю исчерпывающий набор данных об объекте классификации. Методика может применяться для классификации элемента, конструкции, узла сопряжения, материала или иной части строительной системы. Объект классификации может быть идентифицирован как с применением всех

\footnotetext{
${ }^{5}$ Construction Classification System (OmniClass) (OCCS).

${ }^{6}$ Universal classification system for the construction industry (Uniclass 2015).

${ }^{7}$ IS0 12006-2:2015 "Building construction - Organization of information about construction works - Part 2: Framework for classification of information".

${ }^{8}$ АО цнИИПромзданий; Руководитель Н.Н. Трекин. УДК 691, 692; № ААА-А18-118030190104-2. - М., 2018. - 215 с.
} 
разделов, представленных в методике классификации, так и с использованием лишь необходимой их части. Например, при описании строительного материала, такого как щебень гравийный, будет задействован лишь раздел «Материалы и их свойства». Методика может применяться как для описания новых материалов, так и учитывать последствия возможных ремонтов, данные о которых вносятся в элементы информационных моделей строительства, представленных, например, в работах $[2 ; 4]$.

Предлагается для рассмотрения открытая иерархическая система маркировки, базирующаяся на ранее разработанных, таких как КСР, Рубрикатор строительного каталога, Условные обозначения типовых конструкций и др.

Код - А.Б.В.Г.Д.Е.Ж.И.К. (буква «З» пропущена из-за наличия цифры аналогичного написания) (рис. 2).

Буквенные обозначения - отделённые точками разделы информации, которые должны содержать вышеприведённые параметры и характеристики в виде подразделов, групп, подгрупп и, если необходимо классов, подклассов и позиций: $X$; XX; XXX; XXXX. Подразделы, группы и подгруппы могут иметь неограниченное количество позиций, разделённых между собой дефисом (-).

В случае, когда какие-либо разделы или данные отсутствуют, можно оставлять букву, а для подразделов, групп или подгрупп - знак «_».

Расшифровка каждого раздела и его составляющих может быть дана в виде таблиц в электронном или бумажном виде. Сама система и её разделы позволяют вносить дополнительную информацию. Для зданий и сооружений код приведён выше, а для материалов: Ж - раздел «Материалы и их свойства»; 1 - подраздел, например, «Материалы для общестроительных работ»; 2 - группа, например, «Нерудные строительные материалы»; 3 - подгруппа, например, «Щебень»; 4 - класс, например, «Щебень из плотных горных пород»; 5 - подкласс, например, «Щебень из плотных горных пород для строительных работ М1000»; 6 - позиция, например, «Щебень из плотных горных пород для строительных работ М1000, фракция 5-20 мм.

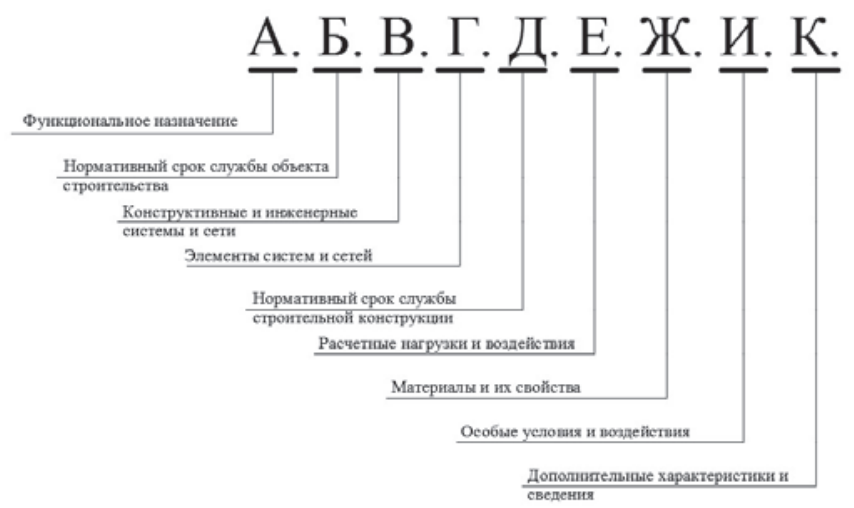

Рис. 2. Схема кодирования элемента информационной системы
Необходимо отметить, что составление таблиц, образцы которых не приведены из-за ограничения объёма публикации, является отдельной большой работой.

Пример возможных структур кода представлен в виде последовательно расширяющейся информации для кода: 1-а.3.1.1-в-1-а.7.1-а50-1-б30-1-в17-2-а10.1-а-1-а-1-а., где 1-а. - Раздел А «Функциональное назначение». Объект непроизводственного назначения. Здание жилищного фонда. 3. - Раздел Б «Нормативный срок службы объекта». Не менее 50 лет. 1. - Раздел В «Конструктивные и инженерные системы и сети». Несущие конструкции. 1-в-1-а. - Раздел Г «Элементы систем и сетей». Железобетонные и бетонные изделия из природных материалов. Сборные железобетонные изделия. Колонны. Колонны железобетонные для многоэтажных зданий. ГОСТ 18979-2014. 7. - Раздел Д «Нормативный срок службы строительной конструкции». Не менее 50 лет. 1-а501-б30-1-в17-2-а10. - Раздел $\mathrm{E}$ «Расчетные нагрузки и воздействия». Статическая. Полезная статическая 50кН. Статическая. Собственный вес 30 кН. Статическая. Предварительное напряжение 17 кН. Динамическая. Пульсационная 10 кН. 1-а-1а-1-а. - Раздел Ж. «Материалы и их свойства». Материалы для общестроительных работ. Нерудные строительные материалы. Щебень. Щебень из плотных горных пород для строительных работ ГОСТ 8267-93. Щебень из плотных горных пород для строительных работ М1000. Щебень из плотных горных пород для строительных работ М1000, фракция 5-10 мм.

\section{Заключение}

Разработка и использование единой универсальной системы классификации позволит уменьшить затраты времени на проектирование и разработку документации для реконструкции и капитального ремонта, формирование различных ведомостей и смет, будет способствовать технически грамотной эксплуатации, обеспечивающей нормативный срок службы зданий и сооружений и снизит трудоёмкость на всех этапах работы с информационной моделью.

\section{Лuтература}

1. Сергеева, 0.Ю. Индустрия 4.0 как механизм формирования «умного» производства [Электронный ресурс] / $0 . Ю$. Сергеева // Нанотехнологии в строительстве. - 2018. - № 2 - С. 100-113. - Режим доступа: http://nanobuild.ru/ru_RU/journal/ Nanobuild-2-2018/100-113.pdf (дата обращения 07.02.2019). DOI: dx.doi.org/10.15828/2075-8545-2018-10-2-100-113

2. Применение композиционных вяжущих и наномодификаторов для получения фибробетона [Электронный ресурс] / Л.А. Урханова, С.А. Лхасаранов, С.Л. Буянтуев, П.К. Хардаев // Нанотехнологии в строительстве. - 2018. - № 6. - С. 91-107. - Режим доступа: https://www.elibrary.ru/item. asp?id=36685800 (дата обращения 06.02.2019). DOI: dx.doi. org/10.15828/2075-8545-2018-10-6-91-107

3. Гранёв, В.В. Разработка и актуализация нормативных документов по проектированию и строительству промышленных 
и гражданских зданий [Электронный ресурс] / В.В. Гранёв, Э.Н. Кодыш // Промышленное и гражданское строительство. - 2014. - № 7. - С. 9-12. Режим доступа: https://elibrary.ru/ item.asp?id=21744339 (дата обращения 05.02.2019).

4. Некоторые свойства порошкового металла при его лазерном напылении для восстановления сечений стальных строительных конструкций [Электронный ресурс] / В.В. Гранёв, А.Н. Мамин, Э.Н. Кодыш [и др.] // Строительные материалы. - 2018. - № 9. - С. 54-57. - Режим доступа: https://elibrary.ru/item.asp?id=35606825 (дата обращения 06.02.2019).

5. Лосев, К.Ю. Создание и внедрение технологии управления жизненным циклом объектов строительства [Электронный ресурс] / К.Ю. Лосев // Промышленное и гражданское строительство. - 2014. - № 11 - С. 80-83. - Режим доступа: https:// elibrary.ru/item.asp?id=22657497 (дата обращения 06.02.2019)

6. Князева, Н.В. Интеграция информационных систем служб эксплуатации с информационной моделью здания [Электронный ресурс] / Н.В. Князева // Промышленное и гражданское строительство. - 2018. - № 9. - С. 68-72. - Режим доступа: https://elibrary.ru/item.asp?id=36296913 (дата обращения 06.02.2019)

7. Мамин, А.Н. Разработка нормативной документации в области эксплуатации зданий и сооружений [Электронный ресурс] / А.Н. Мамин, Э.Н. Кодыш, В.В. Бобров // Промышленное и гражданское строительство. - 2018. - № 7 - С. 24-27. - Режим доступа: https://elibrary.ru/item.asp?id=35146776 (дата обращения 07.02.2019).

\section{References}

1. Sergeeva 0.Yu. Industriya 4.0 kak mekhanizm formirovaniya «umnogo» proizvodstva [Industry 4.0 as a mechanism for the formation of "smart" production]. In: Nanotekhnologii $v$ stroitel'stve [Nanotechnology in Construction], 2018, no. 2, pp. 100-113. Access mode: http://nanobuild.ru/ru_RU/journal/ Nanobuild-2-2018/100-113.pdf (accessed 02/07/2019). DOI: dx.doi.org/10.15828/2075-8545-2018-10-2-100-113 (In Russ., abstr. In Engl.)

2. Urkhanova L.A., Lkhasaranov S.A., Buyantuev S.L., Khardaev P.K. Primenenie kompozitsionnykh vyazhushchikh i nanomodifikatorov dlya polucheniya fibrobetona. In:
Nanotekhnologii v stroitel'stve [Nanotechnology in Construction], 2018, no. 6, pp. 91-107. Access mode: https://www.elibrary.ru/ item.asp?id=36685800 (accessed 07/02/2019). DOI: dx.doi. org/10.15828/2075-8545-2018-10-6-91-107 (In Russ., abstr. In Engl.)

3. Granev V.V., Kodysh E.N. Razrabotka i aktualizatsiya normativnykh dokumentov po proektirovaniyu i stroitel'stvu promyshlennykh i grazhdanskikh zdanii [Development and updating of normative documents on the design and construction of industrial and civil buildings]. In: Promyshlennoe igrazhdanskoe stroitel'stvo [Industrial and Civil Engineering]. 2014, no. 7, pp. 9-12. Access mode: https://elibrary.ru/item.asp?id=21744339 (accessed 05.02.2019). (In Russ., abstr. In Engl.)

4. Granev V.V., Mamin A.N., Kodysh E.N., Eremin K.I., Ershov M.N., Shneiderov G.R. Nekotorye svoistva poroshkovogo metalla pri egolazernom napylenii dlya vosstanovleniya sechenii stal'nykh stroitel'nykh konstruktsii [Some properties of powder metal during itslaser spraying for restoration of sections of steel building structures]. In: Stroitel'nye materialy, 2018, no. 9, pp. 54-57. Access mode: https://elibrary.ru/item.asp?id=35606825 (accessed 02/06/2019). (In Russ., abstr. In Engl.)

5. Losev K.Yu. Sozdanie i vnedrenie tekhnologii upravleniya zhiznennym tsiklom ob"ektov stroitel'stva [Creation and implementation of technology for managing the life cycle of construction objects]. In: Promyshlennoe $i$ grazhdanskoe stroitel'stvo [Industrial and Civil Engineering], 2014, no. 11, pp. 80-83. Access mode: https://elibrary.ru/item.asp?id=22657497 (accessed 02/06/2019). (In Russ., abstr. In Engl.)

6. Knyazeva N.V. Integratsiya informatsionnykh sistem sluzhb ekspluatatsii s informatsionnoi model'yu zdaniya [Integration of information systems of maintenance services with the information model of the building]. In: Promyshlennoe $i$ grazhdanskoe stroitel'stvo [Industrial and Civil Engineering], 2018, no. 9, pp. 68-72. Access mode: https://elibrary.ru/item.asp?id=36296913 (accessed 02/06/2019). (In Russ., abstr. In Engl.)

7. Mamin A.N., Kodysh E.N., Bobrov V.V. Razrabotka normativnoi dokumentatsii $v$ oblasti ekspluatatsii zdanii i sooruzhenii [Development of normative documentation in the field of operation of buildings and structures]. In: Promyshlennoe i grazhdanskoe stroitel'stvo [Industrial and Civil Engineering], 2018, no. 7, pp. 24-27. Access mode: https://elibrary.ru/item.asp?id=35146776 (accessed 02/07/2019). (In Russ., abstr. In Engl.)

Келасьев Николай Геннадьевич (Москва). Кандидат технических наук. Генеральный директор АО «Центральный научно-исследовательский и проектно-экспериментальный институт промышленных зданий и сооружений» (127238, Москва, Дмитровское шоссе, 46, корп. 2. ЦнИИПромзданий). Эл. почта: kelasyev@mail.ru.

Кодыш Эмиль Наумович (Москва). Доктор технических наук, профессор. Главный научный сотрудник АО «Центральный научно-исследовательский и проектно-экспериментальный институт промышленных зданий и сооружений» (127238 Москва, Дмитровское шоссе, 46, корп. 2. ЦНИИПромзданий). Эл. почта: otks@narod.ru. 
Трекин Николай Николаевич (Москва). Доктор технических наук, профессор. Начальник отдела конструктивных систем № 1 А0 «Центральный научно-исследовательский и проектно-экспериментальный институт промышленных зданий и сооружений» (127238 Москва, Дмитровское шоссе, 46, корп. 2. цНИиПромзданий). Эл. почта: otks@narod.ru

Терехов Иван Александрович (Москва). Кандидат технических наук. Доцент ФГАОУ В0 «Российский университет транспорта» [127994, ГСП-4, Москва, ул. Образцова, 9, стр. 9. РУТ (МИИТ)], заведующий сектором конструктивных систем № 1 АО «Центральный научно-исследовательский и проектно-экспериментальный институт промышленных зданий и сооружений» (127238, Москва, Дмитровское шоссе, 46, корп. 2. цнииПромзданий). Эл. почта: otks@narod.ru.

Шмаков Сергей Дмитриевич (Москва). Аспирант. Инженер отдела конструктивных систем № 1 А0 «Центральный научно-исследовательский и проектно-экспериментальный институт промышленных зданий и сооружений» (127238, Москва, Дмитровское шоссе, 46, корп. 2. ЦниИПромзданий). Эл. почта: otks@narod.ru.

Чаганов Алексей Борисович (Киров). Кандидат технических наук. Заведующий кафедрой строительного производства ФГБОУ В0 «Вятский государственный университ» (610000, Киров, ул. Московская, д.36. ВятГУ). Эл. почта: chabpilot@yandex.ru.

Kelasiev Nikolay G. (Moscow). (Moscow). Candidate of Technical Sciences. General Director of the A0 "Central Scientific Research and Experimental Design Institute of Industrial Buildings and Structures" (46 Dmitrovskoe shosse, bldg. 2, Moscow, 127238. Tsniipromzdaniy).E-mail: kelasyev@mail.ru.

Kodysh Emil N. (Moscow). Doctor of Technical Sciences, Professor. Chief Scientific Officer at A0 "Central Scientific Research and Experimental Design Institute of Industrial Buildings and Structures" (46 Dmitrovskoe shosse, bldg. 2, Moscow, 127238. Tsniipromzdaniy).E-mail: otks@narod.ru.

Trekin Nikolay N. (Moscow). Doctor of Technical Sciences, professor. Head of the Department of structural systems No. 1 of the A0 "Central Scientific Research and Experimental Design Institute of Industrial Buildings and Structures" (46 Dmitrovskoe shosse, bldg. 2, Moscow, 127238. Tsniipromzdaniy).E-mail: otks@narod.ru.

Terekhov Ivan A. (Moscow). Candidate of Technical Sciences, Associate Professor of Russian University of Transport [9b9 Obrazcova Ulitsa, Moscow, 127994. RUT (MIIT)], Head of the Structural Systems Sector No. 1 of the A0 "Central Scientific Research and Experimental Design Institute of Industrial Buildings and Structures" (46 Dmitrovskoe shosse, bldg. 2, Moscow, 127238. Tsniipromzdaniy).E-mail: otks@narod.ru.

Shmakov Sergey D. (Moscow). Post-graduate student. Engineer at the Department of structural systems No. 1 of the A0 "Central Scientific Research and Experimental Design Institute of Industrial Buildings and Structures" (46 Dmitrovskoe shosse, bldg. 2, Moscow, 127238. Tsniipromzdaniy). E-mail: otks@narod.ru.

Chaganov Alexey B. (Kirov). Candidate of Technical Sciences, Head of the Department of Construction Production at Vyatka State University. (36, Moskovskaya Street, Kirov, 610000. VyatSU). E-mail: chabpilot@yandex.ru. 